\title{
Biological features of inflammatory breast cancer in North Africa: burden and research priorities
}

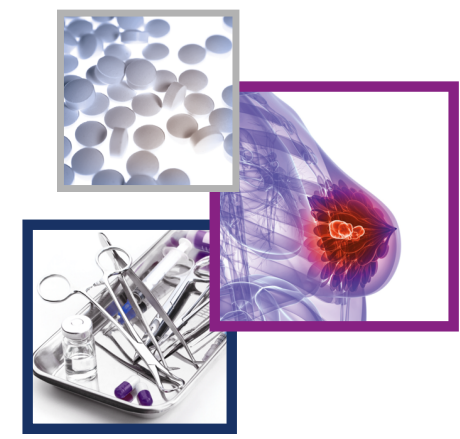

\author{
Nesrine Mejri*,1, Houda El Benna ${ }^{1}$, Fehmi M'ghirbi ${ }^{1}$, Soumaya Labidi ${ }^{1}$, Nouha \\ Daoud $^{1} \&$ Hamouda Boussen ${ }^{1}$ \\ ${ }^{1}$ Medical Oncology Department, Abderrahman Mami Hospital, University of Medicine, University Tunis El Manar, Tunis, Tunisia \\ *Author for correspondence: Tel.: +21 697429 933; nesrinemejriturki@yahoo.fr
}

\section{Practice points}

- Data about inflammatory breast cancer in North Africa is lacking.

- Heterogonous reports show differences between North African countries.

- Several actions with high impact can be initiated to improve outcome.

- Multicenter studies are needed.

We aimed to review all published literature reporting biological data about inflammatory breast cancer (IBC) in populations from North Africa. Methods: We reviewed all studies that evaluated biological features of IBC in six North African countries between 1990 and 2017. Among 118 screened studies, 13 were included, none about Mauritania/Libya. Results: Across the studies, hormonal receptors were positive in $46-69 \%$ of cases, reaching $83 \%$ in Algeria. HER2 was overexpressed in $25-39 \%$ of cases. Recombinant human C protein expression was the highest in Egyptian patients (87\%) compared with other North African populations. Using mRNA expression recombinant human C protein was expressed in $83 \%$ of Tunisian patients. WISP3 gene expression showed positive immunohistochemistry staining in 17\% and mRNA expression in $26.8 \%$ of IBC. Conclusion: Biological aspects of IBC across North Africa show important similarities and differences.

First draft submitted: 11 January 2018; Accepted for publication: 23 May 2018; Published online: 11 September 2018

Keywords: biology $\bullet$ inflammatory breast cancer $\bullet$ North Africa

Inflammatory breast cancer (IBC) is the most fatal form of breast cancer, responsible for a higher number of deaths compared with the non-IBC [1]. The epidemiology of IBC remains under investigation for its relative rarity; the incidence represents approximately $2-3 \%$ of breast cancers (BC) in the USA and $6-10 \%$ in North Africa [2,3]. There has been a considerable investigative effort on IBC in North Africa, where studies demonstrated more accurate epidemiological trends compared with historical reports of IBC (incidence of 5-7\% with tumor-node-metastasis (TNM) staging vs 50\% with PEV [poussée évolutive] classification) [3]. Several studies also reported clinical aspects and described the poor outcome [4]. Clinical definition on which the diagnosis of IBC relies entirely, is now well defined and used in clinical practice since the $6^{\text {th }}$ edition of TNM classification in 2002 than in the additional refinements introduced by the international expert panel on IBC in 2010 [5]. Several studies reported different clinical aspects of IBC between North African patients and western patients in terms of risk factors, presentation and outcome [6,7]. Those differences were also reported within North African countries especially Morocco, Tunisia and Egypt. A study by Soliman et al. comparing IBC in those three countries showed that Egyptian IBC patients had the highest combined erythema, edema, peau d'orange and metastasis rate [8]. Those studies also reported differences in molecular features. Management of breast cancer is currently based on personalized medicine with an important role of tumor biology. Such data about IBC in North Africa are lacking. Most studies are single institution and/or single country. In our paper we reviewed the available published data on biological characteristics of IBC exclusively in six North African countries: Mauritania, Morocco, Algeria, Tunisia, Libya and Egypt. Such a study 
Table 1. Studies reporting biological aspects of inflammatory breast cancer in North Africa.

\begin{tabular}{|c|c|c|c|c|c|}
\hline Study & Year & Region & $\begin{array}{l}\text { Number of } \\
\text { patients }\end{array}$ & Study subject & Ref. \\
\hline Lo et al. & 2009 & Egypt & 46 & RhoC expression and tumor emboli in IBC versus non-IBC & [10] \\
\hline Lo et al. & 2008 & Egypt & 48 & RhoC GTPase IBC (Egypt) versus IBC (USA) & [11] \\
\hline Soliman et al. & 2012 & $\begin{array}{l}\text { Egypt Tunisia } \\
\text { Morocco }\end{array}$ & 482442 & $\begin{array}{l}\text { RhoC GTPase and E-cadherine expression in IBC (Egypt) versus IBC (Tunisia) } \\
\text { versus IBC (Morocco) }\end{array}$ & [8] \\
\hline Ouziane & 2011 & Morocco & 172 & Clinico-pathological characteristics & [12] \\
\hline Ismail et al. & 2014 & Morocco & 72 & Clinico-pathological characteristics & [13] \\
\hline Chaher et al. & 2012 & Algeria & 117 & Molecular and epidemiological characteristics & [14] \\
\hline Hamdi et al. & 2016 & Tunisia & 20 & Prognostic value of circulating miARNs & [15] \\
\hline Le & 2008 & Tunisia & 187 & Prognostic value of dermal eboli in IBC (Tunisia) versus IBC (France) & [6] \\
\hline Marrakchi & 2010 & Tunisia & 41 & WISP3 and RhoC expression between IBC and non-IBCuilk; ,hnb & [16] \\
\hline Mejri et al. & 2015 & Tunisia & 208 & Epidemiological change in IBC & [9] \\
\hline Labidi & 2007 & Tunisia & 100 & Therapeutic outcome & [4] \\
\hline Charafe-Jauffret & 2007 & Tunisia & 91 & $\begin{array}{l}\text { Expression of estrogen receptor, Ki67, E-cadherin, MUC1 and ERBB2 in IBC } \\
\text { (Tunisia) versus IBC (France) }\end{array}$ & [7] \\
\hline Ben Hamida et al. & 2007 & Tunisia & 91 & Distribution of molecular subtypes & [18] \\
\hline
\end{tabular}

may provide some insights on the biological characteristics of the disease and would help improve understanding of its behavior.

\section{Methods}

We conducted a computerized Medline and Google scholar search using the limits 'French' and 'English' about published literature between January 1990 and June 2017, and using the Mesh terms: inflammatory breast cancer*, North Africa*, Mauritania*, Morocco*, Algeria*, Tunisia*, Libya* and Egypt*. References were hand searched for other references. Our inclusion criteria included retrospective studies, case-control studies, cohort studies and clinical trials. In addition, the bibliographies of recent reviews and the authors' personal holdings were checked to ensure that all relevant articles were consulted. A total of 118 studies were identified. The titles and abstracts of all retrieved articles were screened for the relevance. Articles in French were screened and handled for data extraction by the authors who are all fluent in French. Our exclusion criteria were: article about breast cancer not providing specific results about IBC group (46 studies), articles addressing mixed populations with patients from other countries without available data specific to our target population (23 studies) and articles not reporting any data on tumor biology, pathology and molecular pathology (36 studies). Biological data were defined as data including at least pathology features of the tumors such as histological subtype, grade, immunohistochemistry (IHC). Data were extracted using a prepiloted data extraction form and entered into a computerized database conducted specially for the study.

\section{Statistical analysis}

For each study, the effect size (standardized mean difference between treatment and control groups) was calculated and adjusted for sample size. Data were combined in a comprehensive analysis, both by calculating weighted average effect sizes and by looking at the percentage of studies with a positive or negative direction of effect.

\section{Results}

We identified 13 studies reporting data about tumor biology of IBC. Descriptions of those studies: author, year of publication, study population, sample size, and purpose of the study, were presented in Table 1. Across all studies, the median age of IBC was 45 years old, ranging from 42 to 59 years old. Means and standard deviations of age were not reported in major studies.

\section{Pathology aspects}

Grade of IBC was reported in all 13 studies. Grade I was rarely observed in IBC cases in almost all studies, with a rate of $4 \%$ of cases. Across studies, IBC was grade II in $5-83 \%$, and grade III in $17-90 \%$. IBC was grade II in 
Table 2. Distribution of pathological and immunohistochemistry aspects of inflammatory breast cancer among North African studies.

\begin{tabular}{|c|c|c|c|c|c|c|c|c|}
\hline \multirow[t]{2}{*}{ Study (patients) } & \multirow[t]{2}{*}{ Age } & \multicolumn{3}{|c|}{ Grade } & \multicolumn{2}{|c|}{ ER/PR } & \multicolumn{2}{|c|}{ Her2 (\%) } \\
\hline & & I & II & III & Positive & Negative & Positive & Negative \\
\hline An Chi (46) & 46.9 & 0 & 83 & 17 & 61 & 39 & - & - \\
\hline An Ch (48) & 46.9 & 0 & 83 & 17 & 58.1 & 41.9 & - & - \\
\hline $\begin{array}{l}\text { Soliman } \\
\text { Egypt (48) } \\
\text { Tunisia (24) } \\
\text { Morocco (42) }\end{array}$ & $\begin{array}{l}43 \\
46 \\
54\end{array}$ & $\begin{array}{l}0 \\
8.3 \\
0\end{array}$ & $\begin{array}{l}83 \\
12.5 \\
50\end{array}$ & $\begin{array}{l}17 \\
79.1 \\
50\end{array}$ & $\begin{array}{l}61.1 \\
54.6 \\
46.7\end{array}$ & $\begin{array}{l}38.9 \\
45.4 \\
53.3\end{array}$ & - & - \\
\hline Ouziane (172) & 46 & 6 & 54 & 40 & $\begin{array}{l}57.5 \\
E R=49 \\
P R=71\end{array}$ & $\begin{array}{l}42.5 \\
E R=51 \\
P R=29\end{array}$ & 59 & 41 \\
\hline Ismail (72) & 47 & 4 & 36 & $23^{\dagger}$ & 69 & $5.6^{\ddagger}$ & 25.5 & 74.4 \\
\hline Chaher (117) & $59 \%<50$ years & 0 & 63 & 37 & 83 & 17 & 19.8 & 80.2 \\
\hline Hamdi (20) & 49 & 0 & 45 & 55 & $E R=15 P R=20$ & $E R=85 P R=80$ & 65 & 35 \\
\hline Le (187) & & & 55 & 45 & $\begin{array}{l}63.1 \\
E R=50 \\
P R=47\end{array}$ & $\begin{array}{l}34.9 \\
E R=50 \\
P R=53\end{array}$ & - & - \\
\hline Marrakchi (127) & 45 & 0 & 36.5 & 63.5 & $\begin{array}{l}E R=41 \\
P R=27\end{array}$ & $\begin{array}{l}E R=58.5 \\
P R=73\end{array}$ & - & - \\
\hline Mejri (208) & 45 & 10 & & (90) & 48 & 52 & 31 & 69 \\
\hline Labidi (100) & 43.5 & 4 & 39 & $37^{\S}$ & $\begin{array}{l}\mathrm{ER}=17 \\
\mathrm{PR}=12\end{array}$ & $\begin{array}{l}E R=40 \\
P R=27 \mathbb{I}\end{array}$ & - & - \\
\hline $\begin{array}{l}\text { Charafe- } \\
\text { Jauffert } \\
\text { (91) }\end{array}$ & 42 & 2.8 & 67 & 30 & $E R=49$ & $E R=61$ & 39.1 score $2-3$ & 61.1 \\
\hline Ben Hamida (91) & 43 & 3.3 & 66 & 30.7 & $\begin{array}{l}E R=46.1 \\
P R=47.1\end{array}$ & $\begin{array}{l}E R=53.8 \\
P R=52.8\end{array}$ & 33.6 score $2-3$ & 66.7 \\
\hline $\begin{array}{l}\dagger 37 \% \text { unknown } \\
\ddagger 25.4 \% \text { unknown } \\
\S 20 \% \text { unknown } \\
\text { I Unknown status } \\
\text { \#ER: Estrogen recep }\end{array}$ & rs; Her2: Human & do & tor recep & Progester & & & & \\
\hline
\end{tabular}

$83 \%$ of Egyptian IBC patients [8,10,11], 36-54\% of Moroccan IBC patients [12,13], 63\% of Algerian patients [14] and $36-64 \%$ in Tunisian IBC patients [9,15-19]. In the largest series, by our team, $90 \%$ of the IBC cases were grade III [9], and in another IBC series about Tunisian patients by Soliman et al. [8] grade III was seen in $71 \%$ of cases. IHC aspects were reported in all studies with regard to hormonal receptors (HR) (estrogen [ER] and progesterone receptors) and only $7 / 13$ studies reported HER2 status. HR receptors were positive in $15-83 \%$ of IBC cases. In the Algerian series HR were positive in $83 \%$ of IBC cases [14]. HER2 was overexpressed in 25-39\% of cases, in one Moroccan study of 172 patients with IBC, HER2 was overexpressed in 59\% [12]. The unique series where IHC subgroups of IBC were reported is the Algerian series [14]. The majority of IBC tumors were luminal A in $62.4 \%$ of cases, followed by basal in 17.7\%, triple negative in 17.2\%, Luminal B in 9.9\% and HER2+ in 9.9\%. Pathological characteristics of IBC through North African studies was described in Table 2.

\section{Molecular aspects}

Two genes were studied in IBC studies: loss of Human WNT1-inducible-signaling pathway protein 3 (WISP3) and overexpression of recombinant human $\mathrm{C}$ protein (RhoC) guanosine triphosphatase (GTPase). RhoC GTPase is a member of the Ras superfamily of small GTPases, microarray analysis has shown that expression of RhoC is progressively increased as tumors become more aggressively metastatic and that RhoC expression promotes metastasis. The second gene that is WISP3, several mutations in the WISP3 coding sequence are associated with tissue dysplasia and hypertrophy, WISP3 has also growth and angiogenesis inhibitory functions. Those two genes were reported to be consistently and concordantly altered in human IBC.

RhoC expression was evaluated in three studies and WISP3 in one. All studies used IHC staining for RhoC evaluation, with the Tunisian study evaluating both RhoC and WISP3 genes using both IHC and mRNA expression using reverse transcriptase analysis [8-16]. RhoC expression was the highest in Egyptian patients 87\%, in Tunisian 
Table 3. Recombinant human C protein expression evaluation among North African studies.

\begin{tabular}{|lllr|}
\hline Study & RhoC expression (IHC) & miARN expression RohC (RT-PCR) & Ref. \\
\hline Lo al. & Low $13 \%$ & - & \\
\hline Soliman et al. & High $87 \%$ & - & \\
& Low $13 \%$, high $87 \%$ & & \\
& Low $50 \%$, high $50 \%$ & [11] \\
Marrakchi et al. & Low $61.9 \%$, high $38.1 \%$ & Negative $17 \%$ \\
& Negative $31.8 \%$ & Positive $83 \%$ & [16] \\
\hline
\end{tabular}

IHC: Immunohistochemistry.

patients it was over expressed in 50-68\% and in Moroccan patients in 38.1\%. Using mRNA expression RhoC was expressed in $83 \%$ of Tunisian patients. The second gene WISP3 was studied in one study about Tunisian patients [16] showing a positive IHC staining in $17 \%$ and mRNA expression in $26.8 \%$ of IBC. Data about RhoC results are summarized in Table 3.

\section{Discussion}

The present analysis reported a review of pathological and molecular data yet published about IBC in North African countries. It showed heterogeneous aspects across North African IBC patients with several similarities and differences. It also showed lacking representative data about biological aspects of IBC in the region. Molecular and pathological differences in IBC have been noted between Arab and European or USA populations, which could be linked to the aggressive clinical behavior of IBC in Arab women [17-20]. However, despite the fact that North African populations share common demographic features, including a large family size, high rates of consanguinity and rapid population growth [21], data about $\mathrm{BC}$ behavior and especially IBC behavior is rare. In lack of a national cancer registry or a large retrospective study, there are few data about breast cancer in Libya and Mauritania. In a study by Boder $e t$ al. including patients with breast cancer in Libya followed over the course of 5 years, the incidence was approximately 18.89 new cases per 100,000 Libyan females with a median age of 44 years. According to the TNM classification, $11.1 \%$ were $\mathrm{T} 4 \mathrm{~N} 0 \mathrm{M} 0$ or $\mathrm{TxN} 3 \mathrm{M} 0$ without any specific results about $\mathrm{T} 4 \mathrm{~d}$ stage [22]. In the Mauritanian series no data were reported about IBC [23].

Age was the most stable reported aspect. Age at diagnosis of BC in general and of IBC in particular in North Africa was reported to be 10 years younger than western populations in many studies [20], in fact, the age of breast cancer was reported to be around 50 years in North Africa and 62 years in western populations [3]. Such a result can be explained by the young population pyramid [2].

We found a large variation of IHC subgroups of IBC with regard to HR and HER2 expression across North African population. In 2008, a world IBC consortium reported the largest series of 389 IBC samples collected from France, Belgium and USA that analyzed with a standardized platform. It showed that $75 \%$ of IBC belonged to the aggressive subtypes (basal like, HER2, claudin-low and Luminal B), Luminal A subgroup accounted for 19\% of cases [24]. In the Algerian series, $62 \%$ of IBC tumors were Luminal A according to IHC completely different from European/US results. As has been previously published, in these countries the rate of ER+ disease is lower than non-IBC, and the reported rates of HER2 are higher than non-IBC.

It is not very accurate to identify luminal A subtypes from IHC; when IHC is used these are subtype surrogates, and it is critical to identify exactly which markers were used to classify as luminal A-like. Given the low IHC expression of ER noted in many studies, the likelihood of finding luminal A subtypes if it were examined in all of these studies is relatively low. Such results should be taken with caution, certified labs should be encouraged to better characterize breast cancer subtypes more accurately. Such IBC consortium dedicated to patients from North Africa is urgently needed. Multicenter studies within each country and in collaboration with the other countries are mandatory. In order to target limited-resource communities, North African countries need to focus research and interventions on areas that will lead to the maximum impact. IBC screening seems not to be a relevant area of action, since IBC occurs in young women for which mammograms are not accurate and have a clinical history less than 6 months, which can be mis-detected by standard screening programs. North African countries should improve the infrastructure for diagnosing and caring for BC patients. Such facilities are relatively well established in Morocco, Algeria, Tunisia and Egypt with presence of cancer centers; however, such infrastructure is needed in Libya and Mauritania. Filling the lack of HER2 information is a major opportunity to improve outcomes in 
Northern Africa, as the response to anti HER2 drugs is high. Also, focusing on biology of IBC tumors seems to be a relevant area. Identifying prognostic factors and predictive factors would lead to a better use of personalized medicine. Outcome data would provide a more comprehensive picture of the disease in these regions, however, we were unable to find these data in the respective papers and therefore were unable to make conclusions on outcome results.

\section{Future perspective}

There is an urgent need for identification of molecular signature and pathways specific to IBC patients in order to promote drug development for this particular aggressive subgroup of BC. IBC patients should be included in clinical trials with new targeted therapies. Research in the region is lacking, and most advances in the understanding and management of this disease have been based on research conducted in the other northern populations that is not necessarily reproducible in North African patients. Difficulties in conducting such studies were reported by Soliman et al., taking their experience in studying IBC in North African as an example [25]. They elaborated with a checklist, based on logistic, methodology and quality control factors, which summarizes important issues for conducting such studies and may help local researchers overcome obstacles.

Financial \& competing interests disclosure

The authors have no relevant affiliations or financial involvement with any organization or entity with a financial interest in or financial conflict with the subject matter or materials discussed in the manuscript. This includes employment, consultancies, honoraria, stock ownership or options, expert testimony, grants or patents received or pending, or royalties.

No writing assistance was utilized in the production of this manuscript.

\section{Ethical statement}

This work was approved by the local ethical committee.

\section{Open access}

This work is licensed under the Attribution-NonCommercial-NoDerivatives 4.0 Unported License. To view a copy of this license, visit http://creativecommons.org/licenses/by-nc-nd/4.0/

\section{References}

1. Ferlay J, Soerjomataram I, Dikshit R et al. Cancer incidence and mortality worldwide: sources, methods and major patterns in GLOBOCAN 2012. Int. J. Cancer 136(5), E359-E386 (2015)

2. Cobrex M, Bouzbid S, Boffetta P. Features of breast cancer in developing countries, examples from North-Africa. Eur. J. Cancer 50(10), 1808-1818 (2014).

3. Boussen $\mathrm{H}$, Bouzaiene $\mathrm{H}$, Ben Hassouna J et al. Inflammatory breast cancer in Tunisia: reassessment of incidence and clinicopathological features. Semin. Oncol. 35(1), 17-24 (2008).

4. Labidi SI, Mrad K, Mezlini A et al. Inflammatory breast cancer in Tunisia in the era of multimodality therapy. Ann. Oncol. 19(3), 473-480 (2007).

5. Dawood S, Merajver SD, Viens P et al. International expert panel on inflammatory breast cancer: consensus statement for standardized diagnosis and treatment. Ann. Oncol. 22(3), 515-523 (2011).

6. Lê MG, Arriagada R, Contesso G. Dermal lymphatic emboli in inflammatory and noninflammatory breast cancer: a French-Tunisian joint study in 337 patients. Clin. Breast Cancer 6(5), 439-445 (2005).

7. Charafe-Jauffret E, Mrad K, Labidi I et al. Inflammatory breast cancers in Tunisia and France show similar immunophenotypes. Breast 16(4), 352-358 (2007).

8. Soliman AS, Kleer CG, Mrad K et al. Inflammatory breast cancer in North Africa: comparison of clinical and molecular epidemiologic characteristics of patients from Egypt, Tunisia, and Morocco. Breast Dis. 33(4), 159-169 (2011).

9. Mejri N, Boussen H, Labidi S et al. Inflammatory breast cancer in Tunisia from 2005 to 2010: epidemiologic and anatomoclinical transitions from published data. Asian Pac. J. Cancer Prev.16(3), 1277-1280 (2015).

10. Lo A-C, Georgopoulos A, Kleer CG et al. Analysis of RhoC expression and lymphovascular emboli in inflammatory vs non-inflammatory breast cancers in Egyptian patients. Breast Edinb. Scotl. 18(1), 55 (2009).

11. Lo A-C, Kleer CG, Banerjee M, Omar A et al. Molecular epidemiologic features of inflammatory breast cancer: a comparison between Egyptian and US patients. Breast Cancer Res. Treat. 112(1), 141-147 (2008).

12. Ouziane I. Cancer du sein inflammatoire, expérience marocaine, à propos de 172 cas. (2011). (Octoral dissertation) 
13. Ismaili N, Elyaakoubi $\mathrm{H}$, Bensouda $\mathrm{Y}$ et al. Demographic, clinical, pathological, molecular, treatment characteristics and outcomes of nonmetastatic inflammatory breast cancer in Morocco: 2007 and 2008. Exp. Hematol. Oncol. 3(1), 1 (2014).

14. Chaher N, Arias-Pulido H, Terki $\mathrm{N}$ et al. Molecular and epidemiological characteristics of inflammatory breast cancer in Algerian patients. Breast Cancer Res. Treat. 131(2), 437-444 (2012).

15. Hamdi K, Blancato J, Goerlitz D et al. Circulating cell-free miRNA expression and its association with clinicopathologic features in inflammatory and non- inflammatory breast cancer. Asian Pac. J. Cancer Prev. 17(4), 1801-1810 (2016).

16. Marrakchi R, Khadimallah I, Ouerhani S et al. Expression of WISP3 and RhoC Genes at mRNA and protein levels in inflammatory and noninflammatory breast cancer in Tunisian patients. Cancer Invest. 28(4), 399-407 (2010).

17. Najjar H, Easson A. Age at diagnosis of breast cancer in Arab nations. Int. J. Surg. 8(6), 448-452 (2010).

18. Ben Hamida A, Labidi IS, Mrad K et al. Markers of subtypes in inflammatory breast cancer studied by immunohistochemistry: prominent expression of P-cadherin. BMC Cancer 8, 28 (2008).

19. Hamdi K, Goerlitz D, Stambouli N et al. miRNAs in Sera of Tunisian patients discriminate between inflammatory breast cancer and non-inflammatory breast cancer. Springerplus 3, 636-640 (2014).

20. Chouchane L, Boussen H, Sastry KS. Breast cancer in Arab populations: molecular characteristics and disease management implications. Lancet Oncol. 14(10), e417-e424 (2013).

21. Teebi AS, Teebi SA. Genetic diversity among the Arabs. Community Genet. 8(1), 21-26 (2005).

22. Boder JM, Abdallah E, Fathi B et al. Breast cancer patients in Libya: comparison with European and central African patients. Oncol. Lett. 2(2), 323-330 (2011).

23. Baba NDOM, Sauvaget C. Le cancer en Mauritanie: résultats sur 10 ans du registre hospitalier de Nouakchott. Pan Afr. Med. J. doi:10.11604/pamj.2013.14.149.2565 (2013) (Epub ahead of print).

24. Bertucci F, Finetti P, Vermeulen P et al. Genomic profiling of inflammatory breast cancer: a review. Breast 23(5), 538-545 (2014).

25. Soliman AS, Schairer C. Considerations in setting up and conducting epidemiologic studies of cancer in middle- and low-income countries: the experience of a case-control study of inflammatory breast cancer in North Africa in the past 10 years. Cancer Med. 1(3), 338-349 (2012). 